\title{
Long-acting reversible contraceptives
} (LARCs) as harm reduction: a qualitative study exploring views of women with histories of opioid misuse

\author{
Stephani L. Stancil ${ }^{1,2,3^{*}}$, Melissa K. Miller ${ }^{3}$, Alex Duello ${ }^{4}$, Sarah Finocchario-Kessler ${ }^{5}$, Kathy Goggin ${ }^{3,6,7}$,
} Rachel P. Winograd ${ }^{4}$ and Emily A. Hurley ${ }^{3,6}$

\begin{abstract}
Background: The sharp rise in opioid use disorder (OUD) among women coupled with disproportionally high rates of unintended pregnancy have led to a four-fold increase in the number of pregnant women with OUD in the United States over the past decade. Supporting intentional family planning can have multiple health benefits and reduce harms related to OUD but requires a comprehensive understanding of women's perspectives of preventing unintended pregnancies. The purpose of this study was to comprehensively evaluate the knowledge, attitudes and experiences as they relate to seeking contraception, particularly LARCs, among women with active or recovered opioid misuse.
\end{abstract}

Methods: In-depth interviews and focus group discussions with 36 women with current or past opioid misuse were recorded and transcribed. Transcripts were coded by $\geq 2$ investigators. Themes related to contraceptive care seeking were identified and contextualized within the Health Belief Model.

Results: Our analysis revealed seven interwoven themes that describe individual level factors associated with contraceptive care seeking in women with current or past opioid misuse: relationship with drugs, reproductive experiences and self-perceptions, sexual partner dynamics, access, awareness of options, healthcare attitudes/experiences, and perceptions of contraception efficacy/ side effects. Overall, perceived susceptibility and severity to unintended pregnancy varied, but most women perceived high benefits of contraception, particularly LARC. However, perceived barriers were too high for most to obtain desired contraception to support family planning intentions.

Conclusions: The individual-level factors identified should inform the design of integrated services to promote patient-centered contraceptive counseling as a form of harm reduction. Interventions should reduce barriers to contraceptive access, particularly LARCs, and establish counseling strategies that use open, non-judgmental communication, acknowledge the continuum of reproductive needs, explore perceived susceptibility to pregnancy, and utilize peer educators.

Keywords: Contraception, Long-acting reversible contraception (LARC), Opioid use disorder, Substance use, Unintended pregnancy

\footnotetext{
*Correspondence: slstancil@cmh.edu

${ }^{1}$ Division of Adolescent Medicine, Children's Mercy Kansas City, 2401 Gillham Rd, Kansas City, MO 64108, USA

Full list of author information is available at the end of the article
} permits use, sharing, adaptation, distribution and reproduction in any medium or format, as long as you give appropriate credit to the original author(s) and the source, provide a link to the Creative Commons licence, and indicate if changes were made. The images or other third party material in this article are included in the article's Creative Commons licence, unless indicated otherwise in a credit line to the material. If material is not included in the article's Creative Commons licence and your intended use is not permitted by statutory regulation or exceeds the permitted use, you will need to obtain permission directly from the copyright holder. To view a copy of this licence, visit http://creativecommons.org/licenses/by/4.0/. The Creative Commons Public Domain Dedication waiver (http://creativeco mmons.org/publicdomain/zero/1.0/) applies to the data made available in this article, unless otherwise stated in a credit line to the data. 


\section{Background}

In the Unites States, women with opioid use disorder (OUD) have rates of unintended pregnancy that are nearly two-fold higher than the general population [1-3] and the number of pregnant women with OUD has increased four-fold over the past decade [4]. Opioid misuse in pregnancy is associated with higher rates of adverse health outcomes such as pregnancy loss, and neonatal opioid withdrawal, a condition known as Neonatal Abstinence Syndrome (NAS) [5]. NAS increases risks of morbidity (e.g., low birthweight, structural abnormalities, neurological excitability, gastrointestinal dysfunction), medical service needs (i.e., intensive care admission and prolonged hospitalization) and longterm cognitive, learning and behavioral challenges [6, 7]. For mothers, unexpected fetal or neonatal death and NAS, (e.g., related child protection involvement and child removal) can contribute to significant emotional trauma and long-lasting mental health struggles leading to broader social and economic implications [8].

Most women with OUD report wanting to prevent pregnancy intention, but are less likely to use contraception than non-substance using peers at their last sexual encounter [2,9]. As such, unintended pregnancy can be viewed as a harm associated with OUD, and promoting access to and use of reliable contraception as promising new direction for harm reduction among women who wish to avoid pregnancy. Many women with OUD report trying multiple contraceptive methods over time, yet, notably, use of highly effective long-acting reversible contraceptives (LARCs), like the implant and intrauterine device, is less common $[1,10-12]$. Recent studies suggest that most women prefer LARCs over shorter-acting methods, but less than 1 in 5 have ever used one [1, 9-11, 13]. For those with low intention for LARC use, it remains unclear what specific perceptions may contribute [10].

Some studies have tried to provide clarity regarding reproductive health intentions and behaviors in women with substance use. Most individuals with substance use often delay or avoid seeking healthcare due to access barriers or fear of being shamed [14]. Regarding accessing reproductive healthcare specifically, many women with substance use describe numerous barriers such as lack of transportation, lack of knowledge of available health services, fear of law enforcement or child protective services involvement. Surveys focused on women with OUD suggest that limited contraceptive knowledge, fear of side effects or misconceptions about drug-use induced infertility may contribute to underutilization of contraception $[1,10,11,15]$. Potentially influenced by sexual partner dynamics and trauma (e.g., intimate partner violence), pregnancy intentions in women with OUD may also be fluid and complex and impact desire for contraception $[10,16-22]$. However, there remains a gap in knowledge of individual-level factors influencing women's views of LARCs specifically in women engaged in active drug use.

As a part of broader opioid response efforts, the American Academy of Pediatrics and the American College of Obstetrics and Gynecology have endorsed expanding comprehensive contraception access, including LARC, as an essential harm reduction tool in the broader opioid epidemic response [23]. Although some pilot programs have begun to investigate strategies, large-scale expansion has yet to be fully realized [24, 25]. As programs are established, an in-depth understanding of individuallevel factors related to sexual and reproductive health is necessary to support patient-centered care. This study aims to comprehensively evaluate the knowledge, attitudes and experiences regarding contraception, particularly regarding LARCs, among women with active or recovered opioid misuse. Findings from this study will generate a foundational understanding to inform patientcentered contraceptive provision for women with opioid misuse who wish to prevent pregnancy.

\section{Methods}

\section{Setting and participants}

We conducted this prospective, mixed-methods study in two large cities, one mid-size city, and surrounding rural communities in Missouri. Participants were recruited from service organizations within the state's opioid response network (such as federally qualified health centers, substance abuse treatment programs, and syringe exchange programs). English-speaking women aged 18-45 years with self-reported current or recent misuse of opioids, subsequently referred to as opioid misuse, for which they were seeking substance use treatment or harm reduction (e.g., syringe exchange). The study was approved by the Institutional Review Board at Children's Mercy Kansas City.

\section{Data collection}

Data were collected in two phases: (1) in-depth interviews, intended to generate themes in an iterative process and (2) focus group discussions, for consensus and member-checking confirmation of themes [26]. For interviews, we employed a purposive sampling strategy aimed to obtain a demographically diverse group of women from urban/suburban/rural areas, with past/present opioid use, with high/low engagement with service organizations, and varied experience with pregnancy/ childbearing. For focus groups, we recruited women ages 18-45 living in two different substance use recovery housing programs that accept women in early recovery, often with dual diagnoses (e.g., substance use and other 
mental health disorders) and provide ancillary support (e.g., faith-based meetings, support groups, education and employment assistance). There was no overlap in interview and focus group participants. All participants gave verbal informed consent and received a $\$ 25$ gift card.

Interviews were approximately $60 \mathrm{~min}$ in duration. Interviewers used open-ended questions from a semistructured guide based on by previously identified facilitators and barriers to contraception access and also explored emergent themes introduced by the participant [27]. Interview participants also answered closed-ended electronic survey questions regarding their demographics and substance use/reproductive health history. To establish trustworthiness through member-checking, focus group guides were designed to elicit feedback on preliminary findings from in depth interviews and inform remaining discussions [26].

\section{Data analysis}

Analysis of interview transcripts was conducted concurrently with data collection. An iterative process informed subsequent data collection, as the team adjusted sampling priorities and interview content to address gaps [28]. Interviews and focus groups were audio-recorded, transcribed, censored of identifying information, and uploaded into Dedoose (Dedoose Version 7.0.23, Los Angeles, CA: SocioCultural Research Consultants, LLC). Transcripts were coded by $\geq 2$ investigators. Themes were identified and examined alongside the Health Belief Model, [29] a theoretical framework that describes preventative health behaviors as intentional processes influenced by perceived susceptibility to developing the health problem, perceived severity of the consequences of the health problem, perceived benefit versus perceived barriers to engaging in the preventative behavior, cues-toaction that prompt the behavior and self-efficacy, or the individual's perception of their own ability to perform the behavior.

\section{Results}

\section{Interview participants}

Fifteen women with current or past misuse of opioids were interviewed (Table 1). Over half $(60 \%)$ had public health insurance and one-third (33.3\%) had no insurance. None were actively seeking pregnancy and most (85.7\%) were trying to avoid pregnancy. Over half (57.1\%) did not use any method to prevent pregnancy during last vaginal sex. Of those who shared their pregnancy history, $77 \%(10 / 13)$ reported a past pregnancy. An additional 21 women in OUD recovery participated in the two focus groups conducted at residential recovery programs.
Table 1 Participant characteristics of those who completed in-depth interviews $(n=15)$

\begin{tabular}{|c|c|}
\hline Characteristic & Frequency (\%) \\
\hline \multicolumn{2}{|l|}{ Age category } \\
\hline $18-24$ & $2(13 \%)$ \\
\hline $24-34$ & $7(47 \%)$ \\
\hline $35-44$ & $6(40 \%)$ \\
\hline \multicolumn{2}{|l|}{ Race } \\
\hline White or Caucasian & $13(87 \%)$ \\
\hline Black or African American & $2(13 \%)$ \\
\hline \multicolumn{2}{|l|}{ Ethnicity } \\
\hline Hispanic & $4(27 \%)$ \\
\hline \multicolumn{2}{|l|}{ Educational attainment } \\
\hline Some high school & $5(33 \%)$ \\
\hline High school graduate or GED & $2(13 \%)$ \\
\hline Some college or post high-school training & $5(33 \%)$ \\
\hline Undergraduate degree & $2(13 \%)$ \\
\hline Missing* & $1(7 \%)$ \\
\hline \multicolumn{2}{|l|}{ Opioid use status } \\
\hline In active use & $5(33 \%)$ \\
\hline In recovery & $10(67 \%)$ \\
\hline \multicolumn{2}{|l|}{ Residence } \\
\hline Rural & $2(13 \%)$ \\
\hline Suburban & $7(47 \%)$ \\
\hline Urban & $6(40 \%)$ \\
\hline \multicolumn{2}{|l|}{ Relationship status } \\
\hline Married or domestic partnership & $4(27 \%)$ \\
\hline In a committed relationship & $1(7 \%)$ \\
\hline Single & $10(67 \%)$ \\
\hline \multicolumn{2}{|l|}{ Current number of sexual partners } \\
\hline None & $8(53 \%)$ \\
\hline One & $5(33 \%)$ \\
\hline More than one & $1(7 \%)$ \\
\hline Missing/ declined & $1(7 \%)$ \\
\hline \multicolumn{2}{|l|}{ Contraception use at last sex } \\
\hline None & $8(53 \%)$ \\
\hline Withdrawal & $1(7 \%)$ \\
\hline Condom & $3(20 \%)$ \\
\hline Birth control pill & $1(7 \%)$ \\
\hline Injection & $1(7 \%)$ \\
\hline Sterilization & $1(7 \%)$ \\
\hline \multicolumn{2}{|l|}{ Condom at last sex } \\
\hline Yes & $2(13 \%)$ \\
\hline No & $12(80 \%)$ \\
\hline Missing* & $1(7 \%)$ \\
\hline
\end{tabular}

${ }^{*}$ Not answered

\section{Overview of results}

We identified seven overarching themes related to the views of contraception, specifically LARC, among women with opioid misuse: relationship with drugs, reproductive 
experiences and self-perceptions, sexual partner dynamics, healthcare attitudes/experiences, access, awareness of options, and perceptions of contraception efficacy/side effects. These themes were contextualized within the Health Belief Model (HBM) (Table 2, Fig. 1) to explore the connection with behavioral intention [11, 30-33].

\section{Relationship with drugs}

Participants discussed how their relationship with drugs in active use and recovery affected their contraception perceptions and intentions. Active use, they described, is a "pretty demanding lifestyle" where "you do what you have to do to get the drugs". With mental energy concentrated on "chasing the next high," participants looking back on their time in active use claimed that they were not spending "enough time in reality" to think about sexual risks or going through the steps required to get birth control or health services. For many, active use reduced risk perceptions associated with unprotected sex (e.g., "It (pregnancy) never crossed my mind because I'm using. In my brain, I'm just thinking, 'Oh, it's just sex.”'). Some also described being "too full of pride" or too "paranoid" to seek healthcare. Participants generally considered LARCs valuable in active use, giving women "one less thing for me to worry about."

In recovery, women began making looking at their health and future more intentionally. Some considered themselves better prepared for a pregnancy, including those whose pregnancy catalyzed their entry into recovery ("as soon as I found out I was pregnant, I was done"). Most in recovery, however, still believed an unintended pregnancy would bring challenges, preferring to wait until, "I have a stable living environment...so I don't have to worry about feeding, and diapers" or "a non-abusive relationship and more support with trauma." Some also acknowledged cyclic relationship with drugs, wanting to

Table 2 Examples of interconnectedness of themes and Health Belief Model constructs

\begin{tabular}{|c|c|c|}
\hline Illustrative quotes & Themes & HBM constructs \\
\hline $\begin{array}{l}\text { "I don't worry about getting pregnant because I } \\
\text { haven't been able to, according to doctors." }\end{array}$ & $\begin{array}{l}\text { Reproductive experiences and self-perceptions } \\
\text { Healthcare attitudes/experiences }\end{array}$ & Perceived susceptibility to unintended pregnancy \\
\hline $\begin{array}{l}\text { "[Women with OUD] don't want to have any more } \\
\text { children because they'd get them taken away... } \\
\text { I don't want to have another one and think I } \\
\text { can keep it, and one relapse means I never see } \\
\text { it again." }\end{array}$ & $\begin{array}{l}\text { Relationship with drugs } \\
\text { Reproductive experiences and self-perceptions }\end{array}$ & Perceived severity of unintended pregnancy \\
\hline $\begin{array}{l}\text { "I was just like, oh, I just wish I could get pregnant } \\
\text { so he'll keep me forever. He won't hurt me no } \\
\text { more. Maybe he'll love me more if I had his } \\
\text { baby." }\end{array}$ & Sexual partner dynamics & Perceived severity of unintended pregnancy \\
\hline $\begin{array}{l}\text { "So it makes it really hard when they have } \\
\text { expectations of you and want you to have your } \\
\text { insurance cards, and you have to have this or } \\
\text { this, and you ain't got it because you've been } \\
\text { pick-pocketed. But yet, it's like they're saying, } \\
\text { 'Well, we care about your health, but we don't } \\
\text { care about your health because you ain't got } \\
\text { insurance, so we can't help you." }\end{array}$ & $\begin{array}{l}\text { Access } \\
\text { Healthcare attitudes/experiences }\end{array}$ & Perceived barriers to contraception \\
\hline $\begin{array}{l}\text { "But then other girls who have been through it } \\
\text { (pregnancy), they want birth control. But they're } \\
\text { like me; they don't know anything about birth } \\
\text { control. They don't know what kind of doctors. } \\
\text { They don't have financial means to see a doctor. } \\
\text { They don't even know how much it even costs } \\
\text { to get birth control" }\end{array}$ & $\begin{array}{l}\text { Awareness of contraception options } \\
\text { Access }\end{array}$ & Perceived barriers to contraception \\
\hline $\begin{array}{l}\text { "It's (the implant) the best thing that ever hap- } \\
\text { pened to me. It'd be perfect for a woman in } \\
\text { recovery because if we relapse... I'm not going } \\
\text { to go to the doctor." }\end{array}$ & $\begin{array}{l}\text { Reproductive experiences and self-perceptions } \\
\text { Awareness of contraception options } \\
\text { Relationship with drugs }\end{array}$ & Self-efficacy for contraception \\
\hline $\begin{array}{l}\text { "Everybody that I know in my family that have } \\
\text { had their tubes tied, it only went right after } \\
\text { the baby. Everytime. ... And this piece of it } \\
\text { (long-acting reversible contraception) had been } \\
\text { an option, and I was trying to get clean, then } \\
\text { maybe I would have thought about it." }\end{array}$ & $\begin{array}{l}\text { Reproductive experiences and self-perceptions } \\
\text { Access } \\
\text { Awareness of contraception options }\end{array}$ & Cues to action for contraception care-seeking \\
\hline
\end{tabular}




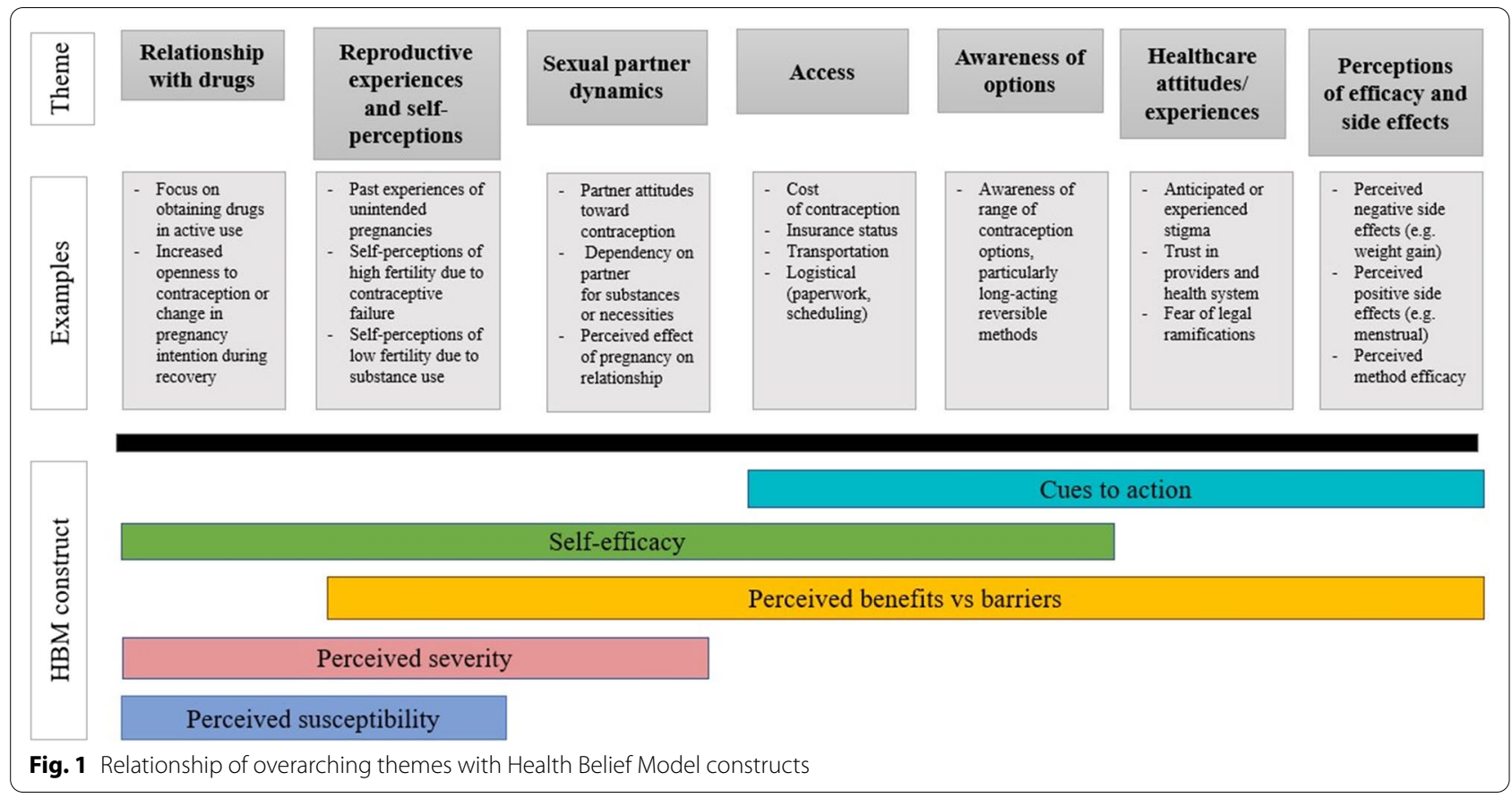

avoid pregnancy in recovery because, "you will probably relapse, more likely than not."

\section{Reproductive experiences and self-perceptions}

Women reported varying reproductive experiences and self-perceptions that influenced diverse levels of perceived susceptibility to unintended pregnancy and the potential value of contraception. Many felt substance use had compromised their fertility (e.g., "using opiates does prevent you from getting pregnant"). Some who felt pregnancy was unlikely described amenorrhea during substance use, long periods of unprotected sex with no resultant pregnancy, or having been told by a health care provider that pregnancy was unlikely.

Perceptions of heightened susceptibility to pregnancy was rarer, but evident in women with a history of unintended pregnancies or a recent pregnancy scare. These experiences led some to consider contraception or sterilization, but others to doubt efficacy of contraceptive measures in general (e.g. "...even if you are being careful, it (pregnancy) can still happen") or specifically for themselves (e.g. "birth control doesn't work for me.").

\section{Sexual partner dynamics}

Women described how sexual partner dynamics could be a facilitator or a barrier to contraception care seeking. While some had partner(s) who were supportive of contraception, others experienced barriers from their partner's desire for children. Some women perceived advantages to pregnancy for preserving or mollifying a relationship. Women often referred to dependent or abusive relationships in active use, where reliance on a partner for shelter, drugs, or food compromised women's ability to seek measures to reduce sexual risks.

"I feel like when you're in addiction and you're with a man that feeds you drugs, you really don't care what you're going through, or the abuse...So, it really doesn't matter if you get pregnant or not."

Further, women who earned money for sex often had to forfeit control over contraception to their "pimp" or partner, who could facilitate or restrict access.

\section{Healthcare attitudes/experiences}

Women who had positive experiences with healthcare were more open to seeking reproductive health services. Women felt that identifying a provider whom they are "willing to trust," comes off as "non-judgmental" and "there to help" was critical to ensure comfort in discussing their reproductive health and pregnancy intentions. They explained how the power of "word of mouth" recommendations from peers could identify trusted health service providers/locations and propagate perceived benefits, or conversely, serve as a barrier if negative experiences were shared. Women valued patient-centered communication with the primary focus being "to make sure you're safe and you're healthy." 
Many, however, recounted previous trauma with reproductive healthcare, making them reluctant to seek it. Some experienced pressure to take a certain type of contraception, for example, being told, "This is what everybody takes, so you're going to" or, being refused a desired method, such as tubal ligation for being "too young." Others recalled experiences with stigma in the healthcare setting, including one woman in active use who described feeling automatically judged because of her tattoos and "junkie" appearance.

Women believed engagement with peer liaisons could help facilitate more positive perceptions of contraception-related health care. Peers (e.g. "someone that has gone through it") could help "make seeing a doctor less intimidating," increase patient comfort, facilitate discussion of sensitive topics and improve trust.

\section{Access}

Access barriers, particularly for LARC and prescription contraception, were numerous and often shaped by healthcare attitudes/experiences. In active use, participants were rarely connected to a primary care or women's health provider, and many did not know where to go to obtain contraception services. For some, a syringe exchange program might be their only point of contact with healthcare. Those connected to healthcare were typically seeing specialists for substance use treatment and were rarely asked about sexual health or contraception. Women also described financial barriers amplified by economic instability, such as prohibitive cost of certain methods, lack of insurance coverage, lack of awareness of insurance or low-cost options, or barriers obtaining necessary prerequisites (e.g., homelessness letter, insurance/financial assistance application) required to access free/low-cost care. Perceived access barriers also included lack of transportation or ability to pay for transportation, and difficulty keeping healthcare appointments when actively using opioids.

Women in recovery cited difficulty in managing "a gazillion different doctors" along with school, work and parenting, favoring an "I can take care of that" approach from trusted provider they may be already seeing. Many did feel that recovery centers or syringe exchange programs could integrate on-site access to contraception, including LARC. "Oh, it's going to take two seconds and I'm going to get some birth control? Hell, yeah!" Another woman explained, "If I had had access like that, that was super simple and fast, I would have done it (LARC)."

\section{Awareness of options}

Awareness of contraceptive options and how to obtain them varied for women. The majority of women in this study were more familiar with condoms, pill and injection and less familiar with LARC. After learning about LARC, women who were initially less aware liked that they would "be easier than remembering to take a pill every day" and "be better than having to go every three months to get a shot". In the context of a demanding relationship with drugs, LARCs gave women in active use "one less thing for me to worry about." For those early in recovery, "we're trying to get our head back, let alone not worrying about, did I take this pill? Did I not take this pill?".

For some women who had previously been pregnant, they recalled getting "tubes tied" which was emphasized as "quick and easy" in the postnatal hospital setting. For many, this was the only option for preventing pregnancy that a healthcare provider had offered to them, and some regret that they did not receive education about other long-acting, yet reversible options. When discussing how to increase awareness of options, women preferred learning about options from a peer (someone with a history of addiction) or from a health care provider recommended by a peer.

\section{Perceptions of contraception efficacy/side effects}

Women had varied perceptions of contraceptive efficacy and side effects. Some women expressed fears of compromising future fertility or potentially harming the fetus if pregnancy occurs while using contraception. Misconceptions about drug-drug interactions were also common (e.g., meth or cocaine causing more harm in combination with hormonal birth control). Women generally perceived valuable benefits of LARCs including the allowance of reversible "long-term" and "short-term" family planning. Yet some feared perceived invasive or complicated procedures required to obtain LARCs (e.g. "I don't want anything in me") or worries the implant may be a "tracking device." One woman got the implant removed after a year because it "freaked (me) out" and subsequently got pregnant while taking oral contraceptive pills. Others were deterred by personal or anecdotal experiences, specifically related to LARCs (e.g., menstrual changes, device breakage, intrauterine device (IUD) movement/expulsion, IUD related infections, partner feeling IUD during sex, perceived ineffectiveness). Many also described positive and negative side effects (e.g., weight gain, amenorrhea, reduced menstrual symptoms and reduced acne) of a specific hormonal contraceptive method, like pills, and projected those same ideas to contraception overall, including LARC. Most women 
did not express understanding of the benefits and risks of individual methods and how they compare to one another. Most women felt that educating about individual contraceptive methods and dispelling myths regarding efficacy and side effects would best be accomplished through the use of a peer educator.

\section{Discussion}

Contraception use among women who wish to prevent pregnancy is a potential means of reducing harms associated with opioid misuse, namely the increased risk of experiencing an unintended pregnancy and of complications for both the fetus and mother. Therefore, improving access to patient-centered contraception provision for women who desire it, regardless of their choices regarding opioid use, represents a promising harm reduction strategy. Our study provides essential context for harm reduction efforts aiming to leverage this strategy by illuminating individual- level factors at the intersection of contraceptive care-seeking and opioid use. Among our sample of Midwestern women with current or recent OUD, contraceptive care seeking was influenced by relationship with drugs, reproductive experiences and selfperceptions, sexual partner dynamics, access, awareness of options, healthcare attitudes/experiences, perceptions of contraception efficacy and side effects. These interconnected themes aligned with constructs of the Health Belief Model (HBM), which has been widely applied to explain contraception intentions and inform interventions to promote reproductive autonomy [11, 30-33]. Contextualized within the common HBM "language," the themes identified in our study provide deeper meaning, layer by layer, specific to women with opioid use. Our findings augment the existing literature to reveal that, despite the presence of contraception desire and even method preference in women with current or past opioid misuse, actual use is often impeded by high perceived barriers, poor self-efficacy, and limited cues to action, particularly for LARCs. Women in our study also share ideas for patient-centered, comprehensive reproductive health care that reduces harms of opioid misuse which, in turn, can facilitate improved quality of life.

Among the themes we identified, access, stands out as one of the most prominent barriers, suggesting systemlevel solutions are needed. When probing specifically about LARCs, women generally emphasized benefits, but believed access to be the biggest challenge. To address access, women recommended integrating reproductive health into their existing OUD care. Other themes, like health care attitudes, reproductive experiences, awareness and a dynamic relationship with drugs suggest benefits of providing comprehensive reproductive care as part of a harm-reduction strategy in settings like recovery centers and syringe exchange programs. Previous literature suggests women with OUD are open to reproductive health care co-occurring with substance use treatment $[9,15$, $25,34,35]$. Opioid-specific public health response has endorsed that comprehensive contraceptive provision, including LARC, is within the scope of practice for a wide variety of clinicians, yet education is needed to improve provider comfort and boost patient access [23].

Concurrent with system-level reform, contraception requires autonomous, intentional care-seeking. Contraceptive counseling and service design should be nondirective, patient-centered and informed by the themes identified in our study with the following strategies:

(1) Utilize open, non-judgmental communication: Women's descriptions of past experiences with health care and desire for future reproductive healthcare overwhelmingly emphasize this need and is consistent with a high perceived emotional cost of seeking care [36]. Given the high rates of trauma among women with OUD, traumainformed care iis a useful counseling framework, particularly around issues related to sexual abuse, coercion, pregnancy loss or termination, and child custody loss that were present in our data and should be inherent in conversations related to reproductive health. Indeed, reducing emotional cost of seeking.

(2) Acknowledge the continuum of reproductive needs in women with OUD, from pregnancy intention to contraception care-seeking. Our findings reveal multifaceted influences on individual reproductive needs including varying sexual partner dynamics, reproductive experiences and self-perceptions and relationship with drugs. The fear that desire for pregnancy in the setting of co-morbidities like substance use disorder may be or has been pathologized by a provider was expressed in our study and is seen in the literature[37]. Such negative health care experiences may prevent women from seeking reproductive care of any kind, reducing opportunity for health promotion, risk reduction counseling or contraceptive education.

(3) Explore individual perceived susceptibility to unintended pregnancy: Women who are substance users are two times more likely to get pregnant if they hold views that they are "unhealthy" or perceive that they cannot get pregnant compared with those without these views [20]. In our study, some women had perceptions of reduced susceptibility to pregnancy similar to previous studies, including beliefs that amenorrhea signified lack of ability to get pregnant and thus negated any need for contraception 
[38]. On the other hand, some participants in our study believed they were overly susceptible, to the point that contraception would not work for them. Identifying individual perceived susceptibility with open-ended questioning can help create a more targeted, patient-centered counseling experience that better educates individual women about their choices.

(4) Use a peer educator when possible to deliver patient education, particularly surrounding inaccurate information, fear of complications and distrust with healthcare. Women in our study and previous literature [11] described misconceptions regarding contraceptive risks or propagated third-party stories that inflated risks. Women in our study provide a solution for improved care: integrating "word of mouth" from a trusted peer to facilitate contraception seeking and use.

\section{Limitations}

Our purposive sampling strategy was designed to promote inclusion of a diverse group of women; however, certain racial and ethnic groups were less represented in the demographics of the organizations and thus less represented in our data Although we do not understand all factors related to underrepresentation of minorities in our partner treatment centers, contributors may include differential experiences with stigma encountered when seeking substance use services [39-42] and preference for faith-based treatment in certain racial andethnic groups over medication assisted treatment [43, 44]. We were able to recruit some women in active drug use. Yet, future work employing targeted recruitment strategies for women in active drug use, specifically those who do not engage with any healthcare system, including syringe exchanges, wwould be important to provide a wide array of perspectives.

\section{Conclusions}

A complex interplay of individual-level factors impacts contraceptive care seeking in women with current or past opioid misuse. Our findings suggest that reduction of barriers through efficient access and comprehensive patient-centered education may, in turn, improve reproductive health care experiences and support individual family planning goals. Suggestions from the women in our study describe their preference to empower peers to share contraceptive information and support one another with strategies that meet their needs. Interventions that address the core themes conveyed by women with opioid misuse may help facilitate patient-centered reproductive health care that meets women "where they are at" to reduce harms associated with opioid exposed unintended pregnancy.

\section{Acknowledgements \\ Not applicable.}

\section{Authors' contributions}

SS made substantial contribution to data acquisition, analysis, interpretation and drafted the manuscript. EH and MM conceived the study and were involved in initial design as well as data acquisition, analysis, interpretation and manuscript preparation. AD, SFK, KG, RW made substantial contributions to study design, data acquisition, analysis, interpretation and manuscript preparation. All authors read and approved the final manuscript.

\section{Funding}

Stephani Stancil is supported by a grant from the Eunice Kennedy Shriver National Institute for Child Health and Human Development (T32 ND069038). This study was supported in part by an NIH Clinical and Translational Science Award grant (UL1 TR002366) to the University of Kansas Medical Center.

Availability of data and materials

The de-identified datasets analyzed during the current study are available from the corresponding author on reasonable request.

\section{Declarations}

Ethics approval and consent to participate

This study was approved by the Children's Mercy Institutional Review Board.

Consent for publication

Data are presented in aggregate form.

\section{Competing interests}

The authors declare no competing interests.

\section{Author details}

${ }^{1}$ Division of Adolescent Medicine, Children's Mercy Kansas City, 2401 Gillham Rd, Kansas City, MO 64108, USA. ${ }^{2}$ Division of Clinical Pharmacology, Toxicology and Therapeutic Innovation, Children's Mercy Kansas City, Kansas City, MO, USA. ${ }^{3}$ Department of Pediatrics, University of Missouri-Kansas City, Kansas City, MO, USA. ${ }^{4}$ Missouri Institute of Mental Health, University of Missouri-St. Louis, St. Louis, MO, USA. ${ }^{5}$ Department of Family Medicine, University Kansas Medical School, Kansas City, KS, USA. ${ }^{6}$ Division of Health Services and Outcomes Research, Children's Mercy Kansas City, Kansas City, MO, USA. ${ }^{7}$ School of Pharmacy, University of Missouri - Kansas City, Kansas City, MO, USA.

Received: 9 April 2021 Accepted: 28 July 2021

Published online: 04 August 2021
References

1. Fischbein RL, Lanese BG, Falletta L, Hamilton K, King JA, Kenne DR Pregnant or recently pregnant opioid users: contraception decisions, perceptions and preferences. Contracept Reprod Med. 2018;3:4.

2. Black Kl, Day CA. Improving access to long-acting contraceptive methods and reducing unplanned pregnancy among women with substance use disorders. Subst Abuse Res Treat. 2016;10(Suppl 1):27-33.

3. Cornford CS, Close HJ, Bray R, Beere D, Mason JM. Contraceptive use and pregnancy outcomes among opioid drug-using women: a retrospective cohort study. PLoS ONE. 2015;10(3):e0116231.

4. Haight SC, Ko JY, Tong VT, Bohm MK, Callaghan WM. Opioid use disorder documented at delivery hospitalization_United States, 1999-2014. MMWR Morb Mortal Wkly Rep. 2018;67(31):845-9.

5. Black Kl, Stephens C, Haber PS, Lintzeris N. Unplanned pregnancy and contraceptive use in women attending drug treatment services. Aust N Z J Obstet Gynaecol. 2012;52(2):146-50.

6. Hudak ML, Tan RC. Neonatal drug withdrawal. Pediatrics. 2012;129(2):e540-60. 
7. Logan BA, Brown MS, Hayes MJ. Neonatal abstinence syndrome: treatment and pediatric outcomes. Clin Obstet Gynecol. 2013;56(1):186-92.

8. SAMHSA. Clinical Guidance for Treating Pregnant and Parenting Women with Opioid Use Disorder and Their Infants. Substance Abuse and Mental Health Services Administration. 2018.

9. Terplan M, Hand DJ, Hutchinson M, Salisbury-Afshar E, Heil SH. Contraceptive use and method choice among women with opioid and other substance use disorders: a systematic review. Prev Med. 2015;80:23-31.

10. Matusiewicz AK, Melbostad HS, Heil SH. Knowledge of and concerns about long-acting reversible contraception among women in medication-assisted treatment for opioid use disorder. Contraception. 2017;96(5):365-9.

11. Smith C, Morse E, Busby S. Barriers to reproductive healthcare for women with opioid use disorder. J Perinat Neonatal Nurs. 2019;33(2):E3-e11.

12. Uusküla A, Raag M, Vorobjov S, Jarlais DD. Another frontier for harm reduction: contraceptive needs of females who inject drugs in Estonia, a cross-sectional study. Harm Reduct J. 2018;15(1):10.

13. Kotha A, Chen BA, Lewis L, Dunn S, Himes KP, Krans EE. Prenatal intent and postpartum receipt of long-acting reversible contraception among women receiving medication-assisted treatment for opioid use disorder. Contraception. 2019;99(1):36-41.

14. Biancarelli DL, Biello KB, Childs E, Drainoni M, Salhaney P, Edeza A, et al. Strategies used by people who inject drugs to avoid stigma in healthcare settings. Drug Alcohol Depend. 2019;198:80-6.

15. MacAfee LK, Harfmann RF, Cannon LM, Minadeo L, Kolenic G, Kusunoki $Y$, et al. Substance use treatment patient and provider perspectives on accessing sexual and reproductive health services: barriers, facilitators, and the need for integration of care. Subst Use Misuse. 2020;55(1):95-107.

16. Pallatino C, Chang JC, Krans EE. The intersection of intimate partner violence and substance use among women with opioid use disorder. Subst Abuse. 2019;42:197-204.

17. El-Bassel N, Marotta PL, Goddard-Eckrich D, Chang M, Hunt T, Wu E, et al. Drug overdose among women in intimate relationships: the role of partner violence, adversity and relationship dependencies. PLoS ONE. 2019;14(12):e0225854.

18. Radcliffe P, Gadd D, Henderson J, Love B, Stephens-Lewis D, Johnson A, et al. What role does substance use play in intimate partner violence? A narrative analysis of in-depth interviews with men in substance use treatment and their current or former female partner. J Interpers Violence. 2019. https://doi.org/10.1177/0886260519879259.

19. Martin SL, Beaumont JL, Kupper LL. Substance use before and during pregnancy: links to intimate partner violence. Am J Drug Alcohol Abuse. 2003;29(3):599-617.

20. MacAfee LK, Harfmann RF, Cannon LM, Kolenic G, Kusunoki Y, Terplan $M$, et al. Sexual and reproductive health characteristics of women in substance use treatment in Michigan. Obstet Gynecol. 2020;135(2):361-9.

21. Klaman SL, Lorvick J, Jones HE. Provision of and barriers to integrating reproductive and sexual health services for reproductive-age women in opioid treatment programs. J Addict Med. 2019;13(6):422-9.

22. Rey CN, Badger GJ, Melbostad HS, Wachtel D, Sigmon SC, MacAfee LK, et al. Perceptions of long-acting reversible contraception among women receiving medication for opioid use disorder in Vermont. Contraception. 2020;101(5):333-7.

23. Patrick SW, Schiff DM. A public health response to opioid use in pregnancy. Pediatrics. 2017;139(3):e20164070.

24. Heil SH, Hand DJ, Sigmon SC, Badger GJ, Meyer MC, Higgins ST. Using behavioral economic theory to increase use of effective contraceptives among opioid-maintained women at risk of unintended pregnancy. Prev Med. 2016;92:62-7.

25. Owens L, Gilmore K, Terplan M, Prager S, Micks E. Providing reproductive health services for women who inject drugs: a pilot program. Harm Reduct J. 2020;17(1):47.
26. Lincoln YS, Guba EG, Pilotta JJ. Naturalistic inquiry. Int J Intercult Relat. 1985;9(4):438-9.

27. Schölmerich VL, Kawachi I. Translating the social-ecological perspective into multilevel interventions for family planning: how far are we? Health Educ Behav. 2016:43(3):246-55.

28. Charmaz K. Constructing Grounded Theory: A practical guide through qualitative analysis. Nurse Res. 2006;13(4):84.

29. Rosenstock IM, Strecher VJ, Becker MH. Social learning theory and the Health Belief Model. Health Educ Q. 1988;15(2):175-83.

30. Chernick LS, Schnall R, Higgins T, Stockwell MS, Castaño PM, Santelli J, et al. Barriers to and enablers of contraceptive use among adolescent females and their interest in an emergency department based intervention. Contraception. 2015;91(3):217-25.

31. Roderique-Davies G, McKnight C, Jonn B, Faulkner S, Lancastle D. Models of health behaviour predict intention to use long acting reversible contraception use. Womens Health (Lond Engl). 2016;12(6):507-12.

32. Timmons SE, Shakibnia EB, Gold MA, Garbers S. MyLARC: a theory-based interactive smartphone app to support adolescents' use of long-acting reversible contraception. J Pediatr Adolesc Gynecol. 2018;31(3):285-90.

33. Berenson $A B$, Rahman M. A randomized controlled study of two educational interventions on adherence with oral contraceptives and condoms. Contraception. 2012;86(6):716-24.

34. Robinowitz N, Muqueeth S, Scheibler J, Salisbury-Afshar E, Terplan M. Family Planning in substance use disorder treatment centers: opportunities and challenges. Subst Use Misuse. 2016;51(11):1477-83.

35. Hurley EA, Duello A, Finocchario-Kessler S, Goggin K, Stancil S, Winograd RP, et al. Expanding Contraception Access for Women With Opioid-Use Disorder: A Qualitative Study of Opportunities and Challenges. Amer J health Promot: AJHP. 2020:34(8):909-18.

36. Edelman NL, Patel H, Glasper A, Bogen-Johnston L. Understanding barriers to sexual health service access among substance-misusing women on the South East coast of England. J Fam Plann Reprod Health Care. 2013;39(4):258-63.

37. Schonberg D, Bennett AH, Sufrin C, Karasz A, Gold M. What women want: a qualitative study of contraception in jail. Am J Public Health. 2015;105(11):2269-74.

38. Drescher-Burke K. Contraceptive risk-taking among substance-using women. Qual Soc Work. 2013;13(5):636-53.

39. Flórez KR, Derose KP, Breslau J, Griffin BA, Haas AC, Kanouse DE, et al. Acculturation and drug use stigma among Latinos and African Americans: an examination of a church-based sample. J Immigr Minor Health. 2015;17(6):1607-14

40. Matthews AK, Corrigan PW, Smith BM, Aranda F. A qualitative exploration of African-Americans' attitudes toward mental illness and mental illness treatment seeking. Rehabil Educ. 2006;20(4):253-68.

41. Davis TA, Ancis J. Look to the relationship: a review of African American women substance users' poor treatment retention and working alliance development. Subst Use Misuse. 2012;47(6):662-72.

42. Kulesza M, Matsuda M, Ramirez JJ, Werntz AJ, Teachman BA, Lindgren KP. Towards greater understanding of addiction stigma: intersectionality with race/ethnicity and gender. Drug Alcohol Depend. 2016;169:85-91.

43. Ward EC, Wiltshire JC, Detry MA, Brown RL. African American men and women's attitude toward mental illness, perceptions of stigma, and preferred coping behaviors. Nurs Res. 2013;62(3):185-94.

44. Zaller ND, Bazazi AR, Velazquez L, Rich JD. Attitudes toward methadone among out-of-treatment minority injection drug users: implications for health disparities. Int J Environ Res Public Health. 2009;6(2):787-97.

\section{Publisher's Note}

Springer Nature remains neutral with regard to jurisdictional claims in published maps and institutional affiliations. 